\title{
A disorder-specific group cognitive behavior therapy for social anxiety disorder in adolescents: study protocol for a randomized controlled study
}

\author{
Nanna Fensman Lassen, Esben Hougaard, Kristian Bech Arendt and Mikael Thastum (D)
}

\begin{abstract}
Background: Social anxiety disorder (SAD) is a common disorder in adolescence associated with extensive distress and long-term impairment. Generic cognitive behavior therapy (CBT) programs for anxiety disorders have shown poorer outcomes for adolescents with SAD than for other anxiety disorders.

Aim: The aim of the present study is to investigate the efficacy of a disorder-specific group cognitive behavior therapy (G-CBT) program for youth SAD, the Cool Kids Anxiety Program - Social Enhanced (CK-E), developed at Macquarie University, Sidney, Australia.

Methods: The study is a randomized controlled trial comparing CK-E to a generic G-CBT program for anxiety disorders. Approximately 96 adolescents aged 12 to 17 years are included with data points at pre- and post-treatment, and at 3 months and 1 year follow-ups.
\end{abstract}

Discussion: The current study will provide more information about the efficacy of diagnosis-specific G-CBT treatment for youth SAD.

Trial registration: ClinicalTrials.gov, NCT03986827. Registered on 14 June 2019.

Keywords: Anxiety, Social anxiety disorder, Cognitive behavior therapy, Randomized controlled trial, Adolescents

\section{Background}

Social anxiety disorder (SAD) most often starts in the early teens with a median age of onset at 12.1 according to the adult sample of the National Comorbidity Survey Replication in the USA [29]. It is among the most common of anxiety disorders, with $5-9 \%$ of adolescents between 13 and 18 years suffering from SAD [10, 16, 29]. Furthermore, studies have shown an increase in SAD from childhood through adolescence $[8,10,12]$.

If left untreated, SAD increases the likelihood of chronicity, loneliness, problems in relation to school activities, and risk of other anxiety disorders, depression, and substance abuse [7, 8, 10, 30, 47]. Adolescence can be regarded as a critical period in the treatment of SAD in order to avoid a chronic developmental course

* Correspondence: mikael@psy.au.dk

Department of Psychology and Behavioural Sciences, Aarhus University, Aarhus, Denmark
$[39,56]$. Thus, development of effective treatment for adolescents suffering from SAD is crucial.

Cognitive behavior therapy (CBT) is the bestdocumented treatment for anxiety disorders in youths [28]. Generic CBT programs for children and adolescents struggling with anxiety disorders have shown substantial effects for other anxiety disorders [5, 46]. However, recent studies indicate that adolescents with SAD have poorer outcomes following generic treatment compared to adolescents struggling with other anxiety disorders like generalized anxiety, separation anxiety, specific phobia, or obsessive compulsive disorder [26, 31, 33, 46].

Different CBT programs specifically designed to treat adolescents with SAD have been developed [9, 24, 25, 37], but there are few direct comparisons of diagnosis-specific treatment of SAD in youth with generic CBT treatment programs [39]. Ingul, Aune and Nordahl [27] compared a 
diagnosis-specific individual CBT (I-CBT) program for youth SAD with generic G-CBT and found diagnosisspecific treatment more effective than generic. However, the different format of the two treatments limits the conclusion as to the role of specific treatment ingredients. Besides, generic G-CBT achieved no change from pre- to post-treatment, which raises doubt about the quality of this treatment.

There is considerable evidence for diagnosis-specific individual CBT for SAD among adults $[36,39]$. There is, however, no evidence of better results of individual CBT for SAD among children and adolescents [39, 64]. In their meta-analysis, Yang et al. [64] found comparable results for individual $(g=1.10)$ and group formats $(g=1.19)$ of psychological interventions for SAD in children and adolescents. They therefore suggested that the group format might be cost-effective in the treatment for youths with SAD. However, results from this meta-analysis should be interpreted with caution due to the high heterogeneity and low quality of most studies.

The present study compares a diagnosis-specific group CBT program for SAD with a generic group CBT program for mixed anxiety disorders. The diagnosis-specific intervention, the Cool Kids Anxiety Program - Social Enhanced (CK-E), was developed at the Centre for Emotional Health at Macquarie University, Sydney, Australia. The program is based on cognitive and behavioral processes that are theorized to maintain $\operatorname{SAD}[13,44]$. CBT including such strategies has been recommended for adults with SAD [39]. The generic program (CK) was essentially identical with the Macquarie Cool Kids Anxiety for adolescent anxiety disorders program (Chilled [45];), but with psychoeducation focusing on SAD. Both treatment programs were group-based with parent involvement.

A further mediational study based on the study data is planned in the future, but the present protocol focuses primarily on the randomized controlled trial (RCT).

\section{Aim and hypothesis}

The aim of the study is to investigate the efficacy of a disorder-specific group CBT program for youth SAD (G-CK-E) compared to a generic group CBT program for anxiety disorders (G-CK). Reduction in anxiety symptoms is expected for both treatment conditions, although we hypothesize better outcome for the enhanced treatment condition.

\section{Methods}

\section{Study design}

The study will take place at the Centre for Psychological Treatment of Children and Adolescents (CEBU), a teaching and research facility at the Department of
Psychology and Behavioral Sciences, Aarhus University, Denmark.

The study is a randomized controlled superiority trial comparing two active groups of treatment: (1) Cool Kids Anxiety Program - Social Enhanced (G-CK-E) and (2) Cool Kids Anxiety Program (G-CK). The study design is a mixed between-within design, with data points pretreatment (T1) and post-treatment (T2), and at followups of 3 and 12 months (T3 and T4). Figure 1 presents a flowchart of the study.

\section{Participants}

Participants are adolescents between 12 and 17 years old who have SAD. Participants are self-referred, based on information on websites, newspaper advertisements, and hand-outs to local general practitioners and educational institutions. Interested families are invited to send a brief description of the adolescent's major problems. An expected recruitment of 16 adolescents half-yearly will yield 96 adolescents completing treatment during a 3year period.

Inclusion criteria are as follows: Participants must be (1) between 12 and 17 years of age; (2) have a SAD diagnosis as their primary disorder.

Exclusion criteria are the following: (1) a diagnosed autism spectrum disorder (ASD); (2) untreated attention deficit hyperactivity disorder (ADHD); (3) psychotic symptoms; (4) current severe self-harm or suicidal ideation; (5) current eating disorder; (6) Clinical Severity Rating (CSR) > 5 on depression (for clarification on CSR see Primary outcome measures); (7) received prior CK treatment within the last 2 years.

\section{Randomization}

Randomization is stratified into two age groups (12-14 and 15-17) using a permuted block design with a fixed block size of 8 at a 1:1 ratio to the CK or the CK-E condition. Randomization is conducted with an online computer random number generator (www.random.org) by an independent secretary. The sequence list is kept concealed from therapists until treatment starts. Participants are not informed about their specific treatment condition.

\section{Intervention}

Both treatment programs were translated from the original manualized, individual Australian CBT program and adjusted to fit a group format by staff at CEBU. Interventions in both treatment conditions consist of 102 $\mathrm{h}$ group sessions with four adolescents and their parents in each group. Sessions 1 through 8 are held weekly, and sessions 9 and 10 at 2 -week intervals. Three months after ending treatment, participants are offered a 1-h 


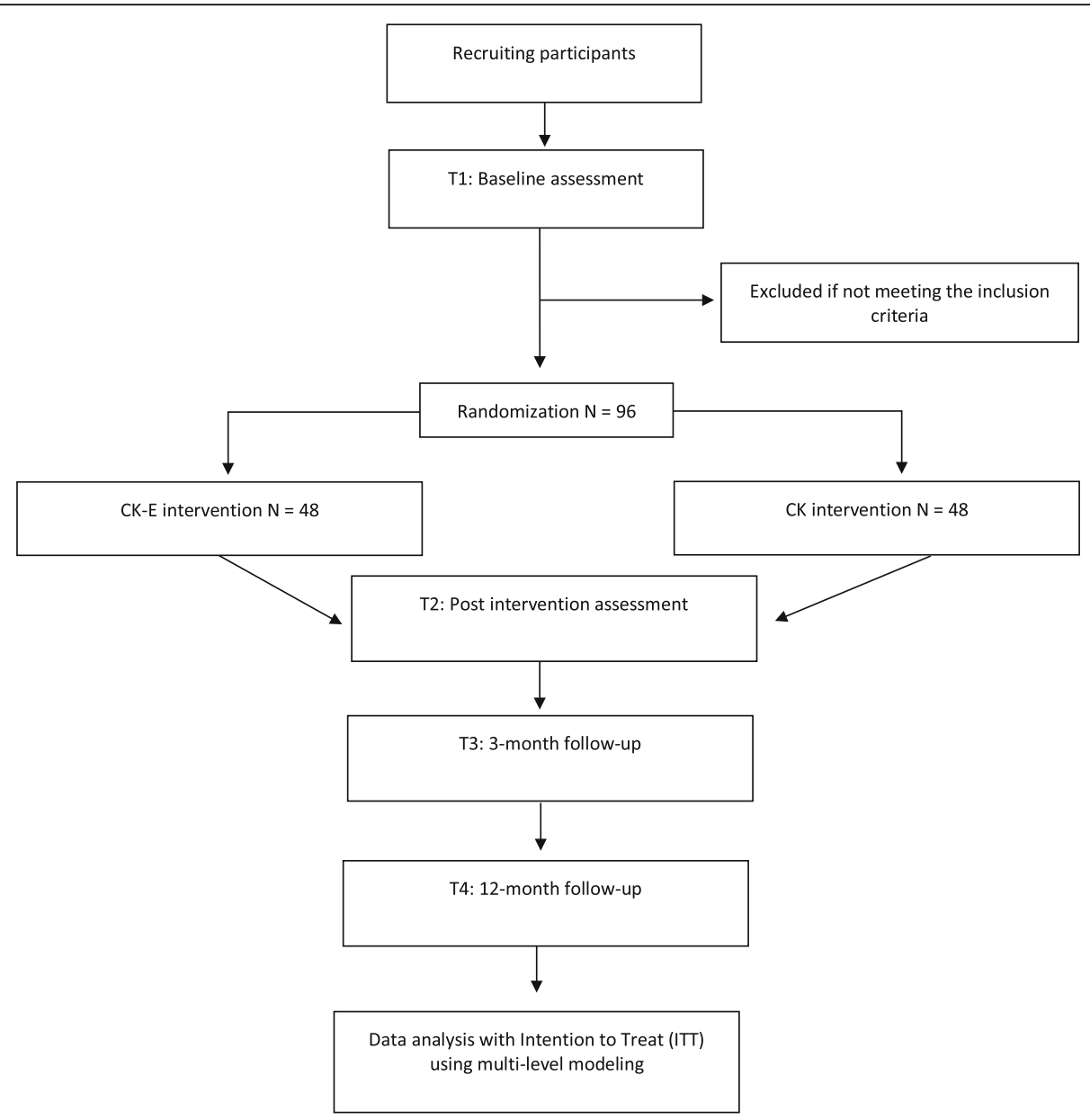

Fig. 1 Flowchart of the study design

booster group session. Table 1 presents an overview of the intervention programs.

Four clinical psychologists from CEBU with experience in the Cool Kids programs (2-5 years) will conduct the treatment intervention. There is one therapist per treatment group, with three to four graduate students attending as practical assistants (helping with exercises and filling out scales).

The clinical psychologists receive weekly peer supervision as well as biweekly group supervision by a specialist in clinical child psychology.

\section{Cool Kids Anxiety Program - Social Enhanced}

The CK-E program is based on the generic Cool Kids Anxiety Program with standard CBT strategies with additional strategies specifically focusing on SAD mechanisms based on the theories of Clark and Wells [13] and Rapee and Heimberg [44]. The additional strategies in CK-E include training in task-focused attention (to reduce self-focus) and focusing on reduction of safetyseeking behaviors. In-session behavioral experiments are used to investigate the role of self-focus and safety-seeking behaviors and to reduce them. Furthermore, cost exposure and cognitive restructuring focusing on overestimation of costs, not of simply likelihood, are essential. Interpersonal exposure tasks with video feedback are used to alter adolescents' distorted negative self-images, and post-event cognitive restructuring is used after challenging exposure tasks in order to reduce post-event rumination.

\section{Cool Kids Anxiety Program}

The standard version of CK is based on standard CBT techniques such as cognitive restructuring and gradual exposure. Additional techniques in the CK manual include simple cool breathing (a relaxing technique) and systematic problem solving.

The therapists are instructed not to use the treatment component specifically included in the enhanced version (e.g., attention training, reduction of safety-seeking behaviors, cost exposure, video feedback, and post-event 
Table 1 Overview of the intervention programs

\begin{tabular}{|c|c|c|c|}
\hline $\begin{array}{l}\text { Session } \\
\text { number }\end{array}$ & Participants & $\begin{array}{l}\text { Session content } \\
\text { CK-E }\end{array}$ & $\begin{array}{l}\text { Session content } \\
\text { CK }\end{array}$ \\
\hline$\overline{S-1}$ & $T, Y, P$ & $\begin{array}{l}\text { - Rapport building } \\
\text { - Psychoeducation } \\
\text { - Worry scale } \\
\text { - SMART goals }\end{array}$ & $\begin{array}{l}\text { - Psychoeducation } \\
\text { - Fears list } \\
\text { - Goals } \\
\text { - Worry scale } \\
\text { - Introduce linking thoughts and feelings }\end{array}$ \\
\hline $\mathrm{S}-2$ & $T, Y, P$ & $\begin{array}{l}\text { - Continue rapport building } \\
\text { - Introduce link between thoughts \& feelings } \\
\text { - Introduce attention training } \\
\text { - Review parent goals }\end{array}$ & $\begin{array}{l}\text { - Introduce cognitive restructuring } \\
\text { (detective thinking) } \\
\text { - Review parent goals }\end{array}$ \\
\hline $\mathrm{S}-3$ & $T, Y, P$ & $\begin{array}{l}\text { - Introduce cognitive restructuring } \\
\text { (detective thinking) } \\
\text { - Introduce rewards }\end{array}$ & $\begin{array}{l}\text { - Continue detective thinking } \\
\text { - Introduce cool breathing } \\
\text { - Introduce rewards }\end{array}$ \\
\hline S-4 & $T, Y, P$ & $\begin{array}{l}\text { - Detective thinking to cost } \\
\text { - Introduce avoidance } \\
\text { - Introduce behavioral experiments } \\
\text { - Conduct in-session experiment }\end{array}$ & $\begin{array}{l}\text { - Introduce exposure } \\
\text { - Design } 1 \text { st stepladder }\end{array}$ \\
\hline S-5 & $\mathrm{T}, \mathrm{P}$ & - Parenting an adolescent with SAD & - Parenting an adolescent with SAD \\
\hline S-6 & $T, Y, P$ & $\begin{array}{l}\text { - Introduce safety traps } \\
\text { - Review experiments } \\
\text { - Introduce experiments to reduce safety behaviors } \\
\text { - Conduct in-session experiment } \\
\text { - Introduce task-focused attention }\end{array}$ & $\begin{array}{l}\text { - Review exposure progress } \\
\text { - Design further stepladders and review useful steps } \\
\text { - Planning in-session exposure }\end{array}$ \\
\hline S-7 & $T, Y, P$ & $\begin{array}{l}\text { - Review safety trap experiments and task-focused attention } \\
\text { - Conduct the video-feedback experiment } \\
\text { - Introduce the importance of obtaining an accurate self- } \\
\text { perception } \\
\text { - Obtaining accurate self-perception using feedback } \\
\text { - Conduct additional in-session experiments }\end{array}$ & $\begin{array}{l}\text { - Review exposure progress } \\
\text { - Simplified detective thinking (in my mind and act as if) } \\
\text { - In-session exposure }\end{array}$ \\
\hline S-8 & $T, Y, P$ & $\begin{array}{l}\text { - Review and revise experiments that utilize feedback } \\
\text { - Introduce post-event processing (detective thinking after a } \\
\text { situation) } \\
\text { - Introduce cost experiments } \\
\text { - Conduct in-session exposure (including an extra challenge } \\
\text { experiment) }\end{array}$ & $\begin{array}{l}\text { - Review of exposure progress } \\
\text { - In-session exposure } \\
\text { - Problem solving }\end{array}$ \\
\hline S-9 & $T, Y, P$ & $\begin{array}{l}\text { - Review and revise extra challenge experiments and post- } \\
\text { event detective thinking } \\
\text { - In-session experiments } \\
\text { - Parents only: Progress review, experiment revision, and } \\
\text { (optional) experiment troubleshooting } \\
\text { - Optional module: Dealing with teasing and bullying }\end{array}$ & $\begin{array}{l}\text { - Revise/add stepladders } \\
\text { - Conduct in-session exposure } \\
\text { - Parents only: Progress review, stepladder revision, and } \\
\text { (optional) stepladder practice troubleshooting }\end{array}$ \\
\hline S-10 & $T, Y, P$ & $\begin{array}{l}\text { - Review of goals } \\
\text { - Maintenance of gains/setbacks } \\
\text { - Future plans }\end{array}$ & $\begin{array}{l}\text { - Review of goals } \\
\text { - Maintenance of gains/setbacks } \\
\text { - Future plans }\end{array}$ \\
\hline Booster & $T, Y, P$ & $\begin{array}{l}\text { - Focusing on maintaining and continuing the progress } \\
\text { - Advise possible further help }\end{array}$ & $\begin{array}{l}\text { - Focusing on maintaining and continuing the progress } \\
\text { - Advise possible further help }\end{array}$ \\
\hline
\end{tabular}

Abbreviations: $S$ session, $Y$ youth, $P$ parent, $T$ therapist, $C K-E$ Cool Kids Anxiety Program - Social Enhanced, $C K$ Cool Kids Anxiety Program

cognitive restructuring), unless they are suggested to do so by the adolescents themselves.

Therapist adherence will be assessed by independent raters on a scale developed at the Macquarie University by watching videotaped therapy sessions and coding for adherence or violations from the treatment manuals.

\section{Measures}

Table 2 presents an overview of the included outcome measures.

\section{Primary outcome measures}

Anxiety Disorders Interview Schedule for DSM-IV, Child and Parent Version (ADIS-IV C/P) [52]

ADIS-IV $C / P$ is a semi-structured diagnostic interview conducted with youth and parents separately to assess the diagnostic criteria for anxiety disorders in accordance with the Diagnostic and Statistical Manual of Mental Disorders (DSM)-IV as well as other disorders often comorbid with anxiety (e.g., depression and ADHD). Severity of the diagnosis is measured on a 9point Likert scale ranging from "not disturbed at all" 
Table 2 Overview of outcome measures, respondents, and assessment points

\begin{tabular}{|c|c|c|c|c|c|}
\hline \multirow[t]{2}{*}{ Measures } & \multirow[t]{2}{*}{ Respondents } & \multicolumn{4}{|c|}{ Time } \\
\hline & & $\overline{\mathrm{T} 1}$ & $\mathrm{~T} 2$ & $\mathrm{~T} 3$ & $\overline{\mathrm{T} 4}$ \\
\hline \multicolumn{6}{|l|}{ Primary outcome measure: } \\
\hline ADIS-IV C/P & $Y, P$ & $\bullet$ & $\bullet$ & $\bullet$ & \\
\hline SPIN & Y & $\bullet$ & $\bullet$ & $\bullet$ & $\bullet$ \\
\hline SCAS & $Y, P$ & $\bullet$ & $\bullet$ & $\bullet$ & $\bullet$ \\
\hline \multicolumn{6}{|c|}{ Secondary outcome measures: } \\
\hline CALIS & $Y, P$ & $\bullet$ & $\bullet$ & $\bullet$ & $\bullet$ \\
\hline S-MFQ & $Y, P$ & $\bullet$ & $\bullet$ & $\bullet$ & \\
\hline NEQ & $Y, P$ & & $\bullet$ & & \\
\hline CHU-9D & Y & $\bullet$ & $\bullet$ & $\bullet$ & $\bullet$ \\
\hline \multicolumn{6}{|l|}{ Other measures: } \\
\hline Background information & $P$ & $\bullet$ & $\bullet$ & $\bullet$ & $\bullet$ \\
\hline DASS & $Y, P$ & $\bullet$ & $\bullet$ & $\bullet$ & \\
\hline CEQ & $Y, P$ & $\bullet a$ & & & \\
\hline ESQ & $Y, P$ & & $\bullet$ & & \\
\hline
\end{tabular}

Abbreviations: $Y$ youth, $P$ parent, $T$ time, ADIS-IV C/P Anxiety Disorders Interview Schedule for DSM-IV, Child and Parent Version, SPIN Social Phobia Inventory, SCAS Spence Children's Anxiety Scale, CALIS Child Anxiety Life Interference Scale, S-MFQ Short version of the Mood and Feelings Questionnaire, NEQ Negative Effects Questionnaire, CHU-9D Child Health Utility 9D, DASS Depression Anxiety Stress Scale, CEQ Credibility/Expectancy Questionnaire, ESQ Experience of Service Questionnaire ${ }^{\mathrm{a}} \mathrm{CEQ}$ is completed by youth and parents after session 1

to "severely disturbed" (0-8). CSR scores of 4 or greater indicate a clinical diagnosis. Separate CSRs are made by youths, parents, and the clinician, but only the CSRs provided by the clinician are used. The most impairing diagnosis, as assessed by the clinician, is considered as the primary diagnosis. Both concurrent validity and test-retest reliability have been established for the anxiety disorder section of ADIS-C $[53,61]$. The ADIS interviews are conducted by clinical psychologists and trained graduate psychology students blinded to treatment condition.

\section{Social Phobia Inventory (SPIN) [14]}

SPIN is a questionnaire used for measuring youths' self-rated SAD symptoms. It includes 17 items covering SAD symptoms of fear, avoidance, and physiological/bodily reactions (trembling, blushing, heart palpitations, and sweating). The adolescents are asked to which degree they have been bothered by these symptoms during the preceding week. Each item is rated on a 5-point Likert scale (0-4). Higher scores indicate higher degree of distress regarding the symptom. The SPIN has been found to have good internal consistency, test-retest reliability, and convergent and divergent validity $[3,14]$. SPIN has demonstrated good psychometric properties for assessing youth SAD $[41,43,59]$.

\section{Spence Children's Anxiety Scale (SCAS and SCAS-P) [55]}

SCAS and SCAS-P are used to measure adolescent- and parent-rated anxiety symptoms. The adolescent version contains 44 items (including six positive filler items), and the parent version contains 38 items. Items are rated on a 4-point Likert scale (0-3). Higher scores indicate higher levels of anxiety. It consists of six subscales reflecting symptoms specifically related to social phobia, panic disorder and agoraphobia, generalized anxiety disorder, obsessive-compulsive disorder, separation anxiety disorder, and fear of physical injury. Each subscale is scored separately; the subscales are then added together for a total score reflecting overall anxiety symptoms. The Danish version of the SCAS has shown good to excellent internal consistency in clinical and non-clinical samples and good test-retest reliability in a non-clinical sample [4].

\section{Secondary outcome measures Child Anxiety Life Interference Scale (CALIS) [34]}

CALIS is used to measure the impact of youth anxiety on various areas of life functioning, including friends, school, extracurricular activities, and family. The impact is evaluated separately by adolescents ( 9 items) and their parents (16 items). Items are evaluated on a 5 -point Likert scale (0-4). Higher scores indicate a higher degree of life interference. CALIS has shown satisfactory internal consistency and moderate test-retest reliability [34].

\section{Short version of the Mood and Feelings Questionnaire (S- MFQ) [19]}

S-MFQ is used in the present study to measure depressive symptoms within the last 2 weeks. The symptoms are evaluated independently by adolescents and parents. The short version includes 13 items rated on a 3-point Likert scale. The Danish version of the full MFQ has shown good psychometric properties [22].

\section{Negative Effects Questionnaire (NEQ) [48]}

NEQ is a self-administered measure of negative effects of psychological treatment. For this study we slightly adjusted the language of NEQ to suit the adolescent age group. Both adolescents and parents are to complete the NEQ, which consists of three parts. The first part asks if specific negative events had occurred during treatment (yes/no). The second part is scored only if the negative event occurred; if so, participants rate how negative the effect was on a 4-point Likert scale, ranging from "not at all" to "extremely" (0-4). Finally, they attribute the negative effect to either "the treatment they receive" (1) or 
"other circumstances" (0). NEQ shows acceptable psychometric properties [48].

\section{Child Health Utility 9D (CHU-9D) [57]}

CHU-9D is a measure of health-related quality of life specifically developed for youth. In this study CHU-9D is rated by the adolescents. The scale consists of nine dimensions: worry, sadness, tiredness, pain, annoyance, school work, daily routine, sleep, and activities, each with one item rated from 1 to 5 . CHU-9D has been validated in Australia and Great Britain indicating good psychometric properties $[11,23]$.

\section{Other measures}

\section{Background information}

Parents will complete a background questionnaire before treatment. This questionnaire includes information regarding the parents' mental and physical health, the adolescent's mental and physical health, family demographics, household income and parents' level of education, adolescent's previous and/or ongoing treatment, and school absenteeism.

\section{Depression Anxiety Stress Scale (DASS) [32]}

DASS is a measure with three subscales on anxiety, depression, and stress. In this study DASS is used by parents to rate their own symptoms. The scale has 42 items, each rated on a 4-point Likert scale $(0-3)$ with higher scores indicating a higher degree of distress. DASS has shown good psychometric properties [2].

\section{Credibility/Expectancy Questionnaire (CEQ) [20]}

CEQ is a self-rated measure addressing the participants' expectancy and credibility about the treatment. Both adolescents and parents complete the questionnaire. CEQ consists of six items, three items regarding credibility and three items regarding expectancy. To meet the requirements of the original version of CEQ, items 1, 2, 3, and 5 are scored on a 9-point scale, while items 4 and 6 are scored on an 11-point scale. Items 4 and 6 are recoded to a 9-point scale before summarizing the scales, as has been done in other studies, e.g., Smeets et al. [54]. Both subscales have shown good test-retest reliability and high internal consistency [20].

\section{Experience of Service Questionnaire (ESQ)}

ESQ (Experience of Service Questionnaire) measures participants' satisfaction with the intervention [6]. There are separate items for parents (10 items) and adolescents (7 items). ESQ includes both positive and negative statements, and items are rated on a 3-point Likert scale $(0-$ 2). ESQ includes open questions with the possibility for qualitative feedback.

\section{Measures for mediational analysis}

Table 3 presents an overview of measures for mediational analysis.

\section{Pre-/post-measures}

Subtle Avoidance Frequency Examination (SAFE) [17]

SAFE is a self-rated measure designed to assess safety behaviors. In this study adolescents complete the questionnaire. SAFE is designed to incorporate active safety behaviors, subtle restriction of behavior, and behaviors aimed at avoiding or concealing physical symptoms. SAFE consists of 32 items ranging on a 5point Likert scale $(0-4)$, with higher scores indicating a higher degree of safety-seeking behaviors. SAFE has shown good psychometric properties [17, 58]. SAFE was originally designed for adults but can be used reliably and validly to assess safety behaviors in adolescents [58].

\section{Children's Automatic Thoughts Scale (CATS) [50]}

CATS, which measures the range of a youth's selfreported negative self-statements, is completed by the adolescents. CATS includes four subscales relating to automatic thoughts on social threat, personal failure, hostility, and physical threat. The full scale has 32 items, each scored on a 5-point Likert scale (0-4), with higher scores indicating higher degrees of negative automatic thoughts. Only two subscales with 20 items are included in the present study, those on thoughts related to social threat and personal failure. The subscales have shown correlations with self-rated SAD in a prior study [38]. CATS has demonstrated good psychometric properties $[38,49,50]$.

\section{Repeated measures}

Mini version of the Social Phobia Inventory (Mini-SPIN) [15] Mini-SPIN is developed as a brief screening instrument for SAD but can also serve as a repeated outcome measurement. Mini-SPIN is completed by the

Table 3 Overview of measures for mediational analysis, respondents, and assessment points

\begin{tabular}{llllllll}
\hline Measures & Respondent & \multicolumn{2}{l}{ Time } & & & \\
\cline { 3 - 7 } & & Pre & S1 & S4 & S7 & S10 & Post \\
\hline SAFE & $Y$ & $\bullet$ & & & & & $\bullet$ \\
CATS & $Y$ & $\bullet$ & & & & & $\bullet$ \\
Mini-SPIN & $Y$ & & & $\bullet$ & $\bullet$ & $\bullet$ & \\
FAQ & $Y$ & & $\bullet$ & $\bullet$ & $\bullet$ & $\bullet$ & \\
PTQ & $Y$ & & $\bullet$ & $\bullet$ & $\bullet$ & $\bullet$ & \\
\hline
\end{tabular}

Abbreviations: $Y$ youth, $P$ parent, $S$ session, SAFE Subtle Avoidance Frequency Examination, CATS Children's Automatic Thoughts Scale, Mini-SPIN Mini version of the Social Phobia Inventory, FAQ Focus of Attention Questionnaire, PTQ Post-event version of the Thought Questionnaire 
adolescents, and it includes three specific items from the original SPIN ("Fear of embarrassment causes me to avoid doing things or speaking to people"; "I avoid activities in which I am the center of attention"; and "Being embarrassed or looking stupid is among my worst fears"). Each item is rated on a 5-point Likert scale (0-4). Higher scores indicate higher degree of distress regarding the symptom. Mini-SPIN has demonstrated high sensitivity and specificity [51] and good psychometric properties for assessing adolescents with SAD [42].

\section{Focus of Attention Questionnaire (FAQ) [62]}

FAQ is a self-rated measure of focus of attention and is completed by the adolescents themselves. FAQ is a 10item scale including two 5-item subscales, self-focused attention and external-focused attention. All items are rated on a 5 -point Likert scale ranging from 1 to $5(1=$ not at all", $5=$ "totally"). Subscale scores are calculated by averaging the five items. A higher score on the two subscales indicates a higher degree of self-focused attention or external focus, respectively. High internal consistency has been reported [63].

\section{Post-event version of the Thoughts Questionnaire (PTQ) [21]}

PTQ is a self-rated measure to assess the degree of postevent processing. Adolescents complete the PTQ. Consistent with prior research $[40,60]$, only the 15 negatively worded items of the PTQ are used in this study. All items are rated on a 5-point Likert scale (0-4). Higher scores indicate a higher degree of post-event rumination. Studies have shown excellent internal consistency $[1,40,60]$.

\section{Economic evaluation}

Cost-utility analyses will be performed by use of the CHU-9D, which was designed to determine how health affects children's lives, and is rated by the youth. The CHU-9D is a generic preference-based measure of health-related quality of life, designed for the estimation of quality-adjusted life years (QALYs) for economic evaluation of healthcare treatment.

\section{Administration of measures}

SPIN, SCAS, CALIS, and CHU-9D are assessed pre- and post-intervention and at the 3months and 1 year followups. ADIS-IV C/P, S-MFQ, DASS, SAFE, and CATS are assessed at pre- and post-intervention and at the 3 months follow-up. NEQ and ESQ are assessed posttreatment. CEQ is completed after session 1. Mini-SPIN is assessed before sessions 1, 4, 7, and 10. FAQ and PTQ are assessed at sessions 1, 4, 7, and 10 .

All questionnaires are administered electronically.
Figure 2 shows an overview for the completed Standard Protocol Items: Recommendations for Interventional Trials (SPIRIT) figure. The SPIRIT checklist is provided as Additional file 1.

\section{Statistical analysis}

The targeted sample size with 47 adolescents per treatment condition (94 in total) will provide an acceptable statistical power $(0.81 ; \alpha=0.05$, two-tailed $)$ to find an effect size of $d=0.65$. Since there is no prior comparable study, it is difficult to estimate an expected effect size. In a study of the Cool Kids Anxiety Program at our clinic, youths with SAD achieved an effect size $(d)$ of -1.0 compared to that of other anxiety disorders (Arendt et al., 2015).

Multilevel linear models (MLMs) are used to compare groups over time (T1, T2, T3, T4) for all outcome variables. MLMs tolerate missing data and therefore do not compromise statistical power unnecessarily. All MLMs are based on intention-to-treat samples. All MLMs are estimated with the maximum likelihood method.

Two sorts of mediational analyses are planned to be conducted: formal mediational analyses with mediators measured pre- and post-therapy by use of the product-of-coefficients method [35] and time-lagged analyses of change with repeated measures within both groups [18].

\section{Discussion}

Developing effective treatment for youth SAD is important because of the high number of adolescents suffering from this disorder. Youth SAD is associated with extensive distress and long-term impairment, which underpins the importance of thorough research. Recent studies indicate that adolescents with SAD have poorer outcomes following generic treatment compared to adolescents struggling with other anxiety disorders [26, 31, 33, 46].

To the best of our knowledge, no prior studies have compared generic and diagnosis-specific CBT for SAD with the same treatment format. An aforementioned study indicates that diagnosis-specific treatment for youth SAD may be more effective than generic treatment [27]. The present study compares a diagnosisspecific G-CBT program with a generic G-CBT program for SAD. The present study will provide more information about the efficacy of diagnosis-specific G-CBT for youth SAD.

\section{Trial status}

A feasibility study with 13 youth (aged $12-16$ years) with a SAD diagnosis was conducted in the fall of 2017. 


\begin{tabular}{|c|c|c|c|c|c|c|c|}
\hline & \multicolumn{7}{|c|}{ STUDY PERIOD } \\
\hline & \multirow{2}{*}{$\begin{array}{c}\text { Enrolment } \\
-t_{1}\end{array}$} & \multirow{2}{*}{$\begin{array}{c}\text { Allocation } \\
0\end{array}$} & \multicolumn{2}{|c|}{ Intervention period } & \multicolumn{2}{|c|}{$\begin{array}{c}\text { Post- } \\
\text { intervention }\end{array}$} & \multirow{2}{*}{$\begin{array}{c}\begin{array}{c}\text { Close- } \\
\text { out }\end{array} \\
t_{5}\end{array}$} \\
\hline TIMEPOINT & & & $t_{1}$ & $t_{2}$ & $t_{3}$ & $t_{4}$ & \\
\hline \multicolumn{8}{|l|}{ ENROLMENT: } \\
\hline Eligibility screen & $x$ & & & & & & \\
\hline Informed consent & $x$ & & & & & & \\
\hline Baseline measures & $x$ & & & & & & \\
\hline $\begin{array}{r}\text { Allocation to CK-E } \\
\text { or CK }\end{array}$ & & $x$ & & & & & \\
\hline \multicolumn{8}{|l|}{ INTERVENTIONS: } \\
\hline \multicolumn{8}{|l|}{$C K-E$} \\
\hline \multicolumn{8}{|l|}{$C K$} \\
\hline \multicolumn{8}{|l|}{ ASSESSMENTS: } \\
\hline ADIS-IV C/P & $x$ & & & & $x$ & $x$ & $x$ \\
\hline SPIN (mini-SPIN) & $x$ & & & $x^{a}$ & $x$ & $x$ & $x$ \\
\hline SCAS & $x$ & & & & $x$ & $x$ & $x$ \\
\hline CALIS & $x$ & & & & $x$ & $x$ & $x$ \\
\hline SAFE & $x$ & & & & $x$ & $x$ & \\
\hline $\begin{array}{r}\text { CATS (social and } \\
\text { failure) }\end{array}$ & $x$ & & & & $\mathrm{x}$ & $\mathrm{x}$ & \\
\hline S-MFQ & $x$ & & & & $x$ & $x$ & \\
\hline CHU-9D & $x$ & & & & $x$ & $x$ & \\
\hline DASS & $x$ & & & & $x$ & $x$ & \\
\hline CEQ & & & & $x^{b}$ & & & \\
\hline $\begin{array}{l}\text { Background } \\
\text { information }\end{array}$ & $x$ & & & & $x$ & $x$ & $x$ \\
\hline NEQ & & & & & $x$ & & \\
\hline ESQ & & & & & $x$ & & \\
\hline FAQ & & & & $x$ & & & \\
\hline PTQ & & & & $\mathrm{x}$ & & & \\
\hline
\end{tabular}

$-t_{1}=$ Baseline assessment (before randomization), $t_{0}=$ randomization, $t_{1}=$ after randomization, $t_{2}=$ during intervention, $\mathrm{t}_{3}=$ postassessment, $\mathrm{t}_{4}=3$-month follow-up, $\mathrm{t}_{5}=12$-month follow-up .

$a=$ Only the mini-SPIN was administred at session 1, 4, 7 and 10. The full SPIN was rated by youth pre- and postassessment, and at 3-month and 1-year follow-ups.

$\mathrm{b}=\mathrm{CEQ}$ is completed after session 1 .

Fig. 2 (See legend on next page.) 
(See figure on previous page.)

Fig. 2 SPIRIT diagram showing schedule of enrollment, allocation, interventions, and assessments. $-t_{1}=$ baseline assessment (before randomization), $0\left(t_{0}\right)=$ randomization, $t_{1}=$ after randomization, $t_{2}=$ during intervention, $t_{3}=$ post-assessment, $t_{4}=3$ months follow-up, $t_{5}=1$

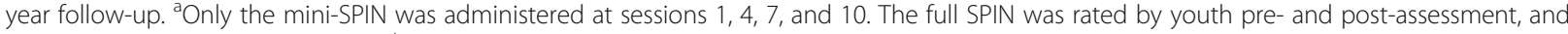
at 3 months and 1 year follow-ups. ${ }^{b}$ CEQ is completed after session 1

Participants were assigned to three treatment groups, all of which used the CK-E approach. The study showed low dropout and high scores on satisfaction and indicated that the manual was adaptable to a group format. Based on the experiences from the feasibility study, some procedures were revised before the RCT. Inclusion of participants to the RCT started in February 2019 and is expected to be finished by September 2021.

\section{Supplementary information}

Supplementary information accompanies this paper at https://doi.org/10. 1186/s13063-019-3885-3.

Additional file 1. SPIRIT 2013 checklist: recommended items to address in a clinical trial protocol and related documents.

\section{Abbreviations}

ADIS-IV C/P: Anxiety Disorders Interview Schedule for DSM-IV, Child and Parent Version; CALIS: Child Anxiety Life Interference Scale; CATS: Children's Automatic Thoughts Scale.; CBT: Cognitive behavioral therapy; CEBU: Center for Psychological Treatment of Children and Adolescents; CEQ: Credibility/ Expectancy Questionnaire; CHU-9D: Child Health Utility 9D; CK: Cool Kids Anxiety Program; CK-E: Cool Kids Anxiety Program - Social Enhanced; CSR: Clinical Severity Rating; DASS: Depression Anxiety Stress Scale; ESQ: Experience of Service Questionnaire; FAQ: Focus of Attention Questionnaire; Mini-SPIN: Mini version of the Social Phobia Inventory; NEQ: Negative Effects Questionnaire; PT: Post-event version of the Thoughts Questionnaire; RCT: Randomized controlled trial; SAD: Social anxiety disorder; SAFE: Subtle Avoidance Frequency Examination; SCAS: Spence Children's Anxiety Scale; S-MFQ: Short version of the Mood and Feelings Questionnaire; SPIN: Social Phobia Inventory

\section{Authors' contributions}

MT is the principal investigator. MT and KBA obtained funding for the project. All authors read and approved the final manuscript.

\section{Funding}

The study was funded by a grant from the Tryg Foundation, Denmark. The study has undergone full external peer review as part of the funding process, and the funding bodies have no other role in the design of the study or in writing the manuscript.

\section{Availability of data and materials}

Not applicable.

\section{Ethics approval and consent to participate}

The Regional Ethics Committee has been consulted, and the study has obtained approval from the Institutional Review Board at Aarhus University (j.nr. 2019-616-000013) and the Institutional Data Protection Agency at Aarhus University (j.nr. 2016-051-000001). Families receive oral and written information and sign an informed consent form. Furthermore, they are informed that participation is voluntary and that their consent can be withdrawn at any time.

\section{Consent for publication}

Not applicable.

\section{Competing interests}

The authors declare that they have no competing interests.
Received: 5 July 2019 Accepted: 5 November 2019

Published online: 21 December 2019

\section{References}

1. Abbott MJ, Rapee RM. Post-event rumination and negative self-appraisal in social phobia before and after treatment. J Abnorm Psychol. 2004;113(1): 136-44. https://doi.org/10.1037/0021-843x.113.1.136.

2. Antony MM, Bieling PJ, Cox BJ, Enns MW, Swinson RP. Psychometric properties of the 42-item and 21-item versions of the Depression Anxiety Stress Scales in clinical groups and a community sample. Psychol Assess. 1998;10(2):176-81. https://doi.org/10.1037/1040-3590.10.2.176.

3. Antony MM, Coons MJ, McCabe RE, Ashbaugh A, Swinson RP. Psychometric properties of the social phobia inventory: further evaluation. Behav Res Ther. 2006;44(8):1177-85. https://doi.org/10.1016/j.brat.2005.08.013.

4. Arendt K, Hougaard E, Thastum M. Psychometric properties of the child and parent versions of Spence Children's Anxiety Scale in a Danish community and clinical sample. J Anxiety Disord. 2014;(28):947-56.

5. Arendt K, Thastum M, Hougaard E. Efficacy of a Danish version of the Cool Kids program: a randomized wait-list controlled trial. Acta Psychiatr Scand. 2015;133(2):109-21. https://doi.org/10.1111/acps.12448.

6. Attride-Stirling J. Development of methods to capture users' views of child and adolescent mental health services in clinical governance reviews [updated 2002]. https://www.corc.uk.net/media/1215/chi_ projectevaluationreport.pdf. Accessed on 1 Sep 2018.

7. Beesdo-Baum K, Knappe S, Fehm L, Hofler M, Lieb R, Hofmann SG, Wittchen $\mathrm{HU}$. The natural course of social anxiety disorder among adolescents and young adults. Acta Psychiatr Scand. 2012;126(6):411-25. https://doi.org/10. 1111/j.1600-0447.2012.01886.x.

8. Beesdo K, Bittner A, Pine DS, Stein MB, Höfler M, Lieb R, Wittchen H-U. Incidence of social anxiety disorder and the consistent risk for secondary depression in the first three decades of life. Arch Gen Psychiatry. 2007;64(8): 903-12. https://doi.org/10.1001/archpsyc.64.8.903.

9. Beidel DC, Turner SM, Morris TL. Behavioral treatment of childhood social phobia. J Consult Clin Psychol. 2000;68(6):1072-80.

10. Burstein M, He JP, Kattan G, Albano AM, Avenevoli S, Merikangas KR. Social phobia and subtypes in the national comorbidity survey-adolescent supplement: prevalence, correlates, and comorbidity. J Am Acad Child Adolesc Psychiatry. 2011;50(9):870-80. https://doi.org/10.1016/j.jaac.2011.06.005.

11. Canaway AG, Frew EJ. Measuring preference-based quality of life in children aged 6-7 years: a comparison of the performance of the CHU-9D and EQ5D-Y — the WAVES pilot study. Qual Life Res. 2013;22(1):173-83.

12. Canino G, Shrout PE, Rubio-Stipec M, Bird HR, Bravo M, Ramírez R, et al. The DSM-IV rates of child and adolescent disorders in Puerto Rico: prevalence, correlates, service use, and the effects of impairment. Arch Gen Psychiatry. 2004;61(1):85-93. https://doi.org/10.1001/archpsyc.61.1.85.

13. Clark DM, Wells A. A cognitive model of social phobia. In: Heimberg R, Liebowitz M, Hope DA, Schneier FR, editors. Social phobia: diagnosis, assessment and treatment. New York: Guilford Press; 1995.

14. Connor KM, Davidson JR, Churchill LE, Sherwood A, Foa E, Weisler RH. Psychometric properties of the Social Phobia Inventory (SPIN). New selfrating scale. Br J Psychiatry. 2000;176:379-86.

15. Connor KM, Kobak KA, Churchill LE, Katzelnick D, Davidson JR. Mini-SPIN: a brief screening assessment for generalized social anxiety disorder. Depress Anxiety. 2001;14(2):137-40.

16. Costello EJ, Egger HL, Angold A. The developmental epidemiology of anxiety disorders: phenomenology, prevalence, and comorbidity. Child Adolesc Psychiatr Clin N Am. 2005;14(4):631-48, vii. https://doi.org/10.1016/j. chc.2005.06.003.

17. Cuming S, Rapee RM, Kemp N, Abbott MJ, Peters L, Gaston JE. A self-report measure of subtle avoidance and safety behaviors relevant to social anxiety: development and psychometric properties. J Anxiety Disord. 2009;23(7): 879-83. https://doi.org/10.1016/j.janxdis.2009.05.002. 
18. Curran PJ, Bauer DJ. The disaggregation of within-person and betweenperson effects in longitudinal models of change. Annu Rev Psychol. 2011;62: 583-619. https://doi.org/10.1146/annurev.psych.093008.100356.

19. Daviss WB, Birmaher B, Melhem NA, Axelson DA, Michaels SM, Brent DA Criterion validity of the Mood and Feelings Questionnaire for depressive episodes in clinic and non-clinic subjects. J Child Psychol Psychiatry. 2006; 47(9):927-34.

20. Devilly GJ, Borkovec TD. Psychometric properties of the Credibility/ Expectancy Questionnaire. J Behav Ther Exp Psychiatry. 2000;31(2):73-86.

21. Edwards SL, Rapee RM, Franklin J. Postevent rumination and recall bias for a social performance event in high and low socially anxious individuals. Cogn Ther Res. 2003;27(6):603-17. https://doi.org/10.1023/a:1026395526858.

22. Eg J, Bilenberg N, Costello EJ, Wesselhoeft R. Self- and parent-reported depressive symptoms rated by the Mood and Feelings Questionnaire. Psychiatry Res. 2018;268:419-25.

23. Furber $\mathrm{G}$, Segal $\mathrm{L}$. The validity of the Child Health Utility instrument (CHU9D) as a routine outcome measure for use in child and adolescent mental health services. Health Qual Life Outcomes. 2015;13:22.

24. Hayward C, Varady S, Albano AM, Thienemann M, Henderson L, Schatzberg AF. Cognitive-behavioral group therapy for social phobia in female adolescents: results of a pilot study. J Am Acad Child Adolesc Psychiatry. 2000;39(6):721-6. https://doi.org/10.1097/00004583-200006000-00010.

25. Herbert JD, Gaudiano BA, Rheingold AA, Moitra E, Myers VH, Dalrymple KL, Brandsma LL. Cognitive behavior therapy for generalized social anxiety disorder in adolescents: a randomized controlled trial. J Anxiety Disord. 2009;23(2):167-77. https://doi.org/10.1016/j.janxdis.2008.06.004.

26. Hudson JL, Keers R, Roberts S, Coleman JR, Breen G, Arendt K, et al. Clinical predictors of response to cognitive-behavioral therapy in pediatric anxiety disorders: the Genes for Treatment (GXT) study. J Am Acad Child Adolesc Psychiatry. 2015;54(6):454-63. https://doi.org/10.1016/j.jaac.2015.03.018.

27. Ingul JM, Aune T, Nordahl HM. A randomized controlled trial of individual cognitive therapy, group cognitive behaviour therapy and attentional placebo for adolescent social phobia. Psychother Psychosom. 2014;83(1):5461. https://doi.org/10.1159/000354672.

28. James AC, James G, Cowdrey FA, Soler A, Choke A. Cognitive behavioural therapy for anxiety disorders in children and adolescents. Cochrane Database Syst Rev. 2013;6:CD004690. https://doi.org/10.1002/14651858. CD004690.pub3.

29. Kessler RC, Avenevoli S, Costello EJ, Georgiades K, Green JG, Gruber MJ, et al. Prevalence, persistence, and sociodemographic correlates of DSM-IV disorders in the National Comorbidity Survey Replication Adolescent SupplementPrevalence of DSM-IV Disorders in the NCS-A. Arch Gen Psychiatry. 2012;69(4):372-80. https://doi.org/10.1001/archgenpsychiatry.2011.160.

30. Kim-Cohen J, Caspi A, Moffitt TE, Harrington H, Milne BJ, Poulton R. Prior juvenile diagnoses in adults with mental disorder: developmental followback of a prospective-longitudinal cohort. Arch Gen Psychiatry. 2003;60(7): 709-17. https://doi.org/10.1001/archpsyc.60.7.709.

31. Kodal A, Fjermestad K, Bjelland I, Gjestad R, Ost LG, Bjaastad JF, et al. Long term effectiveness of cognitive behavioral therapy for youth with anxiety disorders. J Anxiety Disord. 2018;53:58-67. https://doi.org/10.1016/j.janxdis. 2017.11.003

32. Lovibond SH, Lovibond PF. Manual for the Depression Anxiety Stress Scales. Sydney: Psychology Foundation of Australia; 1995.

33. Lundkvist-Houndoumadi I, Thastum M. Anxious children and adolescents nonresponding to CBT: clinical predictors and families' experiences of therapy. Clin Psychol Psychother. 2017;24(1):82-93. https://doi.org/10.1002/cpp.1982.

34. Lyneham HJ, Sburlati ES, Abbott MJ, Rapee RM, Hudson JL, Tolin DF, Carlson SE. Psychometric properties of the Child Anxiety Life Interference Scale (CALIS). J Anxiety Disord. 2013;27(7):711-9. https://doi.org/10.1016/j.janxdis. 2013.09.008.

35. MacKinnon DP, Lockwood CM, Hoffman JM, West SG, Sheets V. A comparison of methods to test mediation and other intervening variable effects. Psychol Methods. 2002;7(1):83-104.

36. Mayo-Wilson E. Psychological and pharmacological interventions for social anxiety disorder in adults: a systematic review and network meta-analysis. Lancet Psychiatry. 2014;1(5):368-76. https://doi.org/10.1016/S22150366(14)70329-3.

37. Melfsen S, Kuhnemund M, Schwieger J, Warnke A, Stadler C, Poustka F, Stangier U. Cognitive behavioral therapy of socially phobic children focusing on cognition: a randomised wait-list control study. Child Adolesc Psychiatry Ment Health. 2011;5(1):5. https://doi.org/10.1186/1753-2000-5-5.
38. Micco JA, Ehrenreich JT. Validity and specificity of the Children's Automatic Thoughts Scale in clinically anxious and non-clinical children. Cogn Ther Res. 2009;33(5):532-6. https://doi.org/10.1007/s10608-009-9230-5.

39. National Institute for Health and Care Excellence (NICE). Social anxiety disorder: recognition, assessment and treatment. London: NICE; 2013. https://www.nice.org.uk/guidance/cg159

40. Perini SJ, Abbott MJ, Rapee RM. Perception of performance as a mediator in the relationship between social anxiety and negative post-event rumination. Cogn Ther Res. 2006;30(5):645-59. https://doi.org/10.1007/s10608-006-9023-z.

41. Ranta K, Kaltiala-Heino R, Koivisto AM, Tuomisto MT, Pelkonen M, Marttunen M. Age and gender differences in social anxiety symptoms during adolescence: the Social Phobia Inventory (SPIN) as a measure. Psychiatry Res. 2007a;153(3):261-70. https://doi.org/10.1016/j.psychres.2006.12.006.

42. Ranta K, Kaltiala-Heino R, Rantanen P, Marttunen M. The Mini-Social Phobia Inventory: psychometric properties in an adolescent general population sample. Compr Psychiatry. 2012;53(5):630-7. https://doi.org/10.1016/j. comppsych.2011.07.007.

43. Ranta K, Kaltiala-Heino R, Rantanen P, Tuomisto MT, Marttunen M. Screening social phobia in adolescents from general population: the validity of the Social Phobia Inventory (SPIN) against a clinical interview. Eur Psychiatry. 2007b;22(4):244-51. https://doi.org/10.1016/j.eurpsy.2006.12.002.

44. Rapee RM, Heimberg RG. A cognitive-behavioral model of anxiety in social phobia. Behav Res Ther. 1997;35(8):741-56. https://doi.org/10.1016/s00057967(97)00022-3.

45. Rapee RM, Lyneham HJ, Schniering C, Wuthrich V, Abbott M, Hudson J, et al. The cool kids child and adolescents anxiety program - therapist manual. Sydney: Centre for Emotional Health, Macquarie University; 2006.

46. Reynolds S, Wilson C, Austin J, Hooper L. Effects of psychotherapy for anxiety in children and adolescents: a meta-analytic review. Clin Psychol Rev. 2012;32(4):251-62. https://doi.org/10.1016/j.cpr.2012.01.005.

47. Roza SJ. Stable prediction of mood and anxiety disorders based on behavioral and emotional problems in childhood: a 14-year follow-up during childhood, adolescence, and young adulthood. Am J Psychiatry. 2003;160(12):2116-21. https://doi.org/10.1176/appi.ajp.160.12.2116.

48. Rozental A, Kottorp A, Forsstrom D, Mansson K, Boettcher J, Andersson G, et al. The Negative Effects Questionnaire: psychometric properties of an instrument for assessing negative effects in psychological treatments. Behav Cogn Psychother. 2019:47(5):559-72. https://doi.org/10.1017/ s1352465819000018

49. Schniering CA, Lyneham HJ. The Children's Automatic Thoughts Scale in a clinical sample: psychometric properties and clinical utility. Behav Res Ther 2007;45(8):1931-40. https://doi.org/10.1016/j.brat.2006.09.009.

50. Schniering CA, Rapee RM. Development and validation of a measure of children's automatic thoughts: the Children's Automatic Thoughts Scale. Behav Res Ther. 2002:40(9):1091-109.

51. Seeley-Wait E, Abbott MJ, Rapee RM. Psychometric properties of the minisocial phobia inventory. Prim Care Companion J Clin Psychiatry. 2009;11(5): 231-6. https://doi.org/10.4088/PCC.07m00576.

52. Silverman WK, Nelles WB. The Anxiety Disorders Interview Schedule for Children. J Am Acad Child Adolesc Psychiatry. 1988;27(6):772-8. https://doi. org/10.1097/00004583-198811000-00019.

53. Silverman WK, Saavedra LM, Pina AA. Test-retest reliability of anxiety symptoms and diagnoses with the Anxiety Disorders Interview Schedule for DSM-IV: child and parent versions. J Am Acad Child Adolesc Psychiatry. 2001;40(8):937-44. https://doi.org/10.1097/00004583-200108000-00016.

54. Smeets RJ, Beelen S, Goossens ME, Schouten EG, Knottnerus JA, Vlaeyen JW. Treatment expectancy and credibility are associated with the outcome of both physical and cognitive-behavioral treatment in chronic low back pain. Clin J Pain. 2008;24(4):305-15. https://doi.org/10.1097/AJP. 0b013e318164aa75.

55. Spence SH. A measure of anxiety symptoms among children. Behav Res Ther. 1998;36(5):545-66.

56. Spence SH, Rapee RM. The etiology of social anxiety disorder: an evidencebased model. Behav Res Ther. 2016;86:50-67. https://doi.org/10.1016/j.brat. 2016.06.007

57. Stevens K. Valuation of the Child Health Utility 9D Index. PharmacoEconomics. 2012;30(8):729-47.

58. Thomas SA, Daruwala SE, Goepel KA, De Los Reyes A. Using the Subtle Avoidance Frequency Examination in adolescent social anxiety assessments. Child Youth Care Forum. 2012:41(6):547-59. https://doi.org/10.1007/s10566012-9181-y. 
59. Tsai CF, Wang SJ, Juang KD, Fuh JL. Use of the Chinese (Taiwan) version of the Social Phobia Inventory (SPIN) among early adolescents in rural areas: reliability and validity study. J Chin Med Assoc. 2009;72(8):422-9. https://doi. org/10.1016/s1726-4901(09)70399-5.

60. Wong QJJ, Gregory B, McLellan LF, Kangas M, Abbott MJ, Carpenter L, et al. Anticipatory processing, maladaptive attentional focus, and postevent processing for interactional and performance situations: treatment response and relationships with symptom change for individuals with social anxiety disorder. Behav Ther. 2017;48(5):651-63. https://doi.org/10.1016/j.beth.2017.03.004.

61. Wood JJ, Piacentini JC, Bergman RL, McCracken J, Barrios V. Concurrent validity of the anxiety disorders section of the Anxiety Disorders Interview Schedule for DSM-IV: child and parent versions. J Clin Child Adolesc Psychol. 2002;31(3):335-42. https://doi.org/10.1207/s15374424jccp3103_05.

62. Woody SR. Effects of focus of attention on anxiety levels and social performance of individuals with social phobia. J Abnorm Psychol. 1996; 105(1):61-9.

63. Woody SR, Chambless DL, Glass CR. Self-focused attention in the treatment of social phobia. Behav Res Ther. 1997;35(2):117-29.

64. Yang L, Zhou X, Pu J, Liu L, Cuijpers P, Zhang Y, et al. Efficacy and acceptability of psychological interventions for social anxiety disorder in children and adolescents: a meta-analysis of randomized controlled trials. Eur Child Adolesc Psychiatry. 2019;28(1):79-89. https://doi.org/10.1007/ s00787-018-1189-x.

\section{Publisher's Note}

Springer Nature remains neutral with regard to jurisdictional claims in published maps and institutional affiliations.

Ready to submit your research? Choose BMC and benefit from:

- fast, convenient online submission

- thorough peer review by experienced researchers in your field

- rapid publication on acceptance

- support for research data, including large and complex data types

- gold Open Access which fosters wider collaboration and increased citations

- maximum visibility for your research: over $100 \mathrm{M}$ website views per year

At $\mathrm{BMC}$, research is always in progress.

Learn more biomedcentral.com/submissions 